\title{
Existing Status of the Passbook Applica- tion and Prospect Research
}

\author{
Liu Xia \\ Sanya Aviation Tourism College, Sanya, Hainan, 572000
}

\begin{abstract}
"QR code" is an important interface of O2O (Online To Offiline). How to accomplish the online and offline interaction via the interface and how to connect the mobile internet with the enterprises' system to interact with customers and upgrade their satisfaction at meanwhile are greatly concerned by enterprises in the mobile internet era. At the moment, Apple Inc. adds Passbook to its iOS6 system for personal notes collection. It has initially occupied $\mathrm{O} 2 \mathrm{O}$ interface of the mobile terminal, which has promoted the development of mobile payment to a certain extent. This paper tends to analyze the prospect of Passbook application on the basis of its existing status and in combination of characteristics of the technique.
\end{abstract}

Keywords: QR code; Passbook; Application

The mobile internet has been focusing on "QR code" (Quick Response Code) in 2012 that users may dispose information automatically with the automatic recognition of their cell phone snapshot. In the commercial development mode of QR code, there's no doubt the Passbook promoted in Apple's iOS6 system is mostly concerned by the public with over 20 renowned enterprises both at home and abroad taking the initiatives to add the supporting function of Passbook in such a short time, less than two months from the end of September when the download was available up to now; and the custom- ers have reflected positive experience effect.

\section{Introduction of Passbook}

\subsection{Definition of Passbook}

As a new application in iOS6 cell phone operation system as promoted by Apple Inc., Passbook is a kind of notes management tool with four vouchers under management at present, including the boarding pass, tickets, store membership cards and coupons. As the notes under Passbook are documents in the specific form of .pkpass, the merchants may produce their own Passbook notes with specific tools.

\subsection{Obtaining of Passbook}

\subsubsection{Import from the Merchants' APP Application}

Visit the merchants' APP via the cell phone terminal, click "save as" to your cell phone's Passbook after the QR code or the bar code is available therein. Then you may find various notes as collected when visiting Passbook of your cell phone. It is the most prevailing producing and use method at present.

1.2.2 Import from Website Browse with

Cell Phone

The merchants make Passbook notes with specific tools and then publicize them on net. The consumers may open the electronic voucher on the website with their iPhone's browser, click "save as" to their Passbook and save them on their own cell phone for the future call. 


\subsubsection{Import by Mail Browse with Cell} Phone

Send the ready electronic vouchers in the form of .pkpass to consumers via email attachment so that the consumers may add the vouchers to their Passbook upon opening the mail with their iPhone.

\subsection{Commercial Values of Passbook}

1.3.1 Collection and Management of Personal Notes

The function will integrate various APP notes including the movie tickets, boarding pass, bonus cards and gift cards, etc. so as to manage various APP coupons and notes in a unified manner and at the meanwhile liberate the customers from various APP and notes. If they don't want to reuse a specific electronic voucher in their Passbook, they may delete it from the Passbook.

\subsubsection{Long-Distance Instant Information Renewal}

As Passbook is adopting Apple's mature Push Notification technique, it is capable of renewing information on the electronic vouchers promptly from long distance. For example, when you've changed your air ticket after calling the airline company, the electronic voucher within your Passbook may renew relevant information automatically; when the boarding gate is changed, Passbook will give a clue on your cell phone timely. 1.3.3 Note Sent by the Merchants Based on the Geographical Location

Passbook may indicate automatically the membership cards and coupons of the neighboring merchants according to the user's location. When the user is walking towards a relevant store or location, the cell phone will automatically remind $\mathrm{him} / \mathrm{her}$ of the coupon and movie ticket of the neighboring merchants as saved within the Passbook. As the note is sent by the server's analysis of the card's geographical location, no equipment is demanded at the store.
For example, when you are passing a Starbucks, the Passbook will pop up a note in remind of you that you're in the neighboring of a Starbucks and you may use relevant Starbucks coupon and gift card.

1.3.4 Merchants' Notice Cost Saved with the Coupon Usage Rate Increased

Passbook has replaced the previous QR code and short message sending with cost saved. As the coupon can be produced directly and saved on the cell phone for timely use whenever demanded, it has completely cancelled the communication fees for word short message and QR code message with great cost saved in favor of the merchants.

Passbook itself is able of reminding users of coupons that will be mature. As the merchants' geographical locations are indicated on coupons within the Passbook, the users will be reminded upon entering the merchant's store to promote the consumption. With these coupons whenever and wherever you are, the use rate is greatly increased.

\subsubsection{A Brand-New Market Promotion} Channel

When no electronic voucher is available within the Passbook, it will be connected to Appstore where available applications are recommended, including the application of various living service tickets, so that the users may find the exact service as demanded very conveniently and download it to their Passbook. This method is much more effective and convenient when compared with other market promotion channels.

\section{Application Cases of Passbook}

At present, not too many applications are supported by Passbook, primarily focusing on foreign market such as United Airlines, Lufthansa Airlines, Fandango Movies as a movie ticket reservation website, Live National concert sales website, W 
Hotels reservation website, U.S. retailer Target, cosmetic retailer Sephora to Go, U.S. pharmacy e-commerce Walgreens and Apple's retail store, etc.

At present, applications which support Passbook in China includes Ctrip, QQ movie ticket, Qunar, ddcoupon, tuan800, jienu, douban movie and Air China.

\subsection{Application Cases of Airline Ser- vices}

\subsubsection{Mode Introduction}

As the air tick purchase voucher: the APP for air ticket purchase via the cell phone terminal. Send the finished order to Passbook after successful reservation of the air ticket, which shall be considered as the voucher for successful ticket purchase.

As the check-in boarding pass: a Passbook voucher will be produced by the App upon the check-in procedures dealt with, the seat selected and the passenger's information confirmed via the cell phone terminal of the airline company so that the airline company's name, the airline number, the departure time and address, the boarding gate and the seat number will be definitely indicated on the voucher with the code attached. Click it and save to Passbook.

When the passenger arrives at the airport with any luggage for transportation, he/she may scan the boarding pass at the check-in counter's QR code identifier to go through the luggage transportation procedures; in case of no luggage, he/she may check-in directly by scanning the boarding pass on the Passbook with relevant information available to the security checker who will carry out relevant security checking with the passenger's ID card. The QR code scanned at the security checking will be imported to the departure system promptly. When the boarding gate is confirmed or changed, the customer terminal will send relevant information instantly to the passenger with the boarding time and gate notified. When the passenger is boarding, he/she has only to scan the boarding pass on his/her Passbook and the data will be returned to the departure system with the passenger's status changing from CHECKED IN to LIFT/BOARDED. Thus the whole operation from the check-in to the boarding is completed.

\subsubsection{Primary Application Cases}

2.1.2.1 As the air ticket purchase voucher

Ctrip and Qunar have supported the Passbook ticket producing since the end of September of this year.

Ticket cases: use Ctrip to purchase the air ticket. Open "Ctrip" APP on your cell phone and send the finished order to your Passbook after successful reservation of the air ticket.

2.1.2.2 As the check-in boarding pass

American Airlines, United Airlines, Lufthansa Airlines and Delta Air Lines have promoted the Passbook boarding pass in succession since the end of September of this year and Air China also promoted a Passbook check-in service in the APP on October 8 of this year with news stating that China Southern Airlines would also promote the Passbook checkin in the near future.

Boarding pass case: Air China is using the Passbook boarding pass.

2.1.3 Characteristic Summary of the Use Mode

2.1.3.1 Electronic Boarding Pass for Convenient Check-in

Log on the airline company's APP, click the check-in and input relevant airline information, then APP will produce a QR code boarding pass automatically, click it to save on the Passbook so that the passenger may go through the boarding procedures upon his/her arrival at the airport. The electronic boarding pass produced by APP has completely replaced the previous short message and email, which enables the check-in much more convenient.

2.1.3.2 Airline Information Sent Properly 
In case of any change of the airline information when the passenger has used the Passbook electronic boarding pass, the airline company may send the latest airline information to the passenger via Passbook for the sake of the passenger and alleviating the information issuance pressure of the airline company's ground service at meanwhile.

\subsection{Application Case for Commercial Purposes}

\subsubsection{Mode Introduction}

The Passbook application based on the life services primarily includes such three types as the tickets, store's membership cards and coupons, in which, the tickets primarily involve the movie tickets and the tickets for concert, vocal concert and games, etc.

Users don't have to print the paper notes. They just scan the electronic notes saved on their Passbook at the exact location to complete the traditional ticket examination.

\subsubsection{Primary Application Cases}

2.2.2.1 Ticket: use "QQ movie ticket" to purchase the movie ticket

Open the APP of "QQ movie ticket" on your cell phone and click "add to Passbook" after successful purchase.

2.2.2.2 Store's membership card: consumption at Starbucks

First of all, the customer has to deposit at the Starbucks's membership card. The cell phone's Passbook will indicate the balance with the membership account and password certified. When the user tend to purchase a cup of coffee at Starbucks, he/she just have to scan the bar code on his/her intelligent cell phone screen with the Starbucks' card reader to finish the payment; at the same time, the balance of his/her Passbook membership card is renewed promptly.

2.2.2.3 Coupon: dd coupon

Open the AA of "dd coupon" and click "Passbook" to save on the cell phone's Passbook after successful reservation.

\subsection{Characteristic Summary of the Use Mode}

2.3.1 Standardization of the Coupon and Reservation Method

Passbook has settled various coupons in a standard manner with its notes integration function so that the customers may find them correctly and promptly. It has been able of managing personal notes in a more centralized manner instead of previous methods of short message confirmation or order within APP.

2.3.2 Orientation Improvement with Coupon Sent as per the Geographical Location

The merchants may send coupons and order information to customers in the neighborhood according to their geographical location so as to make prompt promotion and send the latest coupon to the customers' hand via Passbook.

\section{Development Prospect of Passbook}

\subsection{Advantages of Passbook}

\subsubsection{Systematic Application and Easy Promotion}

The latest statistics show that 100 million users have renewed iOS6 all over the world with iPhone users in China accounting for about $20 \%$ of that worldwide. As an application of iOS6, the merchants only have to add the function to their APP in favor of the customers, as a great easy way for promotion.

3.1.2 Convenient Use with Cell Phone

Management

The users may check their orders and coupons with Passbook so that it is no longer necessary to thumb through the applications and short messages for using the coupon. In this sense, Passbook has brought great convenience to the users for its unified management of notes.

3.1.3 Convenient for the Merchants to Lock Target Consumers 
With the geographical location and notice sent, a new service information channel with much more continence is provided to the merchants who may send relevant information to their target customers with specific direction and location, which has enabled the issuance of various commodity information much more targeted.

3.1.4 Convenient for the Merchants to Improve the Service Quality

Whenever a coupon is about to be mature, the customer is walking into a store or the note information is renewed, Passbook will give a clue. This precise marketing has improved the merchants' service quality.

\subsection{Limited Functions of Passbook}

\subsubsection{Relatively Small Effect on the En-} tire Industry Chain

The QR code and the bar code are primarily adopted by Passbook to carry the notes information. Although it is an important import of $\mathrm{O} 2 \mathrm{O}$, it will not exert subversive effect on the entire industry chain.

3.2.2 Customers' Habits Available for Cultivation

At present, iOS6 hasn't been issued for long time with relatively few cooperation merchants in China; at the same time, Passbook is only applicable to iphone users with iOS6 system available. In this sense, the target users are not prevailing.

To take "QQ movie ticket" as an example, the customers can adopt an alternative way by producing the QR code in the APP, which is also available for timely clue. In this sense, the Passbook's advantage in notes collection cannot stand out in case of few cell phone notes. Thus the customers' habits remain for cultivation.

\subsubsection{Merchants' Hardware Support as}

\section{Demanded}

Although the cooperation merchants are free from sending short massage or email, the bar code identifier, as an in- vestment in the hardware, shall be available with them to identify various notes, especially in terms of the boarding pass because the business system is required to support the bar code scan identification and the information renewal to a certain extent.

\subsubsection{Online Payment Not Supported}

After the issuance of new version Google Wallet, it could not only realize Passbook's function of electronic notes management but also possess a complete consumption flow with the online payment.

At present, Passbook does not support the online payment, which means the users have to purchase the deposit card in advance to realize the normal consumption of coupons and cards saved on Passbook. Its convenience is greatly decreased from this aspect while compared with Goolge Wallet.

\section{Application Prospect of Passbook}

Several airline companies have taken the initiatives in the QR code application in many fields ranging from the $\mathrm{QR}$ code identification of name cards to the micro letter enterprise friends addition with QR code and the interaction with customers on Twitter via QR code. Nevertheless, QR code still enjoys a wide prospect in the airline service and the production and operation field.

\subsection{Addition of the Import Method of Passbook}

Passbook is primarily adopted for managing and renewing the boarding pass, tickets, store's membership cards and coupons saved on the user's cell phone with three main methods available for importing Passbook, that is, the cell phone application, email and website.

The airline enterprises usually possess many formats involving the management of the boarding pass, tickets and membership cards to different extents, which de- 
mand the mobile application be compatible of the Passbook import function or capable of sending the importing format of Passbook with the email attachment or the importing format of saving Passbook during the website browse. Under the existing situation, the said three import methods may enable the customers to use various vouchers at any time so that the voucher use rate is increased and the customer resource is cultivated as a result.

\subsection{Emphasis on the Information Sending by Passbook}

Passbook can be regarded as an information sending tool in the long term so that the airline information can be sent correctly at the first time to passengers for the sake of their rational time arrangement, which is conducive to improve the service quality of Hainan Airline. Besides, Passbook can be used for other commercial purposes to lock target consumers by sending information based on the geographical location so as to increase the use rate of membership cards and coupons

\subsection{System's Recognition and Sup- port of Passbook as Demanded}

The merchants have to support Passbook with the business system to a certain extent while equipped with the QR code identifier for using Passbook. To take the Passbook boarding pass as an example, the QR code identifier shall be available at the check-in, security examination and boarding gate for scanning the boarding pass on Passbook with the data imported to the departure system promptly. In this sense, relevant aviation business system is demanded to support Passbook in the overall operation.

\subsection{Check-in Forms Enriched with Passbook as Involved}

At present, not too many Passbook products are integrated in China, but several airline companies have taken the initiatives. They have to add this function to their application involving the ticket sales within the enterprise on the condition that their airline business system supports the bar code identification; accordingly, the passengers may make use of the cell phone's application to complete the check-in and produce the Passbook boarding pass in replace of the traditional check-in method, which is much more convenient. In addition, they may consider purchasing ticket and boarding via a simple Passbook voucher when the Passbook connection is available. It can greatly simplify their various operations.

\section{Summary}

QR code has been involved in people's life rapidly with the online and offline interaction mode becoming increasingly abundant as realized by the QR code. As a function of iOS6, Passbook has vast users of Apple naturally and provided them with very convenient use mode by managing and integrating electronic notes. Although it has only been available for download for less than two months, many cases have indicated that it can be adopted by enterprises as an effective tool to improve their customer's satisfaction with certain effects already achieved in terms of improving the work flow, advancing the sales and marketing effect as well as reducing the cost.

\section{References}

[1] http://link.springer.com/referencewor kentry/10.1007/0-387-26336-5_1501

[2] http://en.wikipedia.org/wiki/Passbook

[3] http://en.wikipedia.org/wiki/Passbook (application)

[4] http://www.36kr.com/p/173693.html

[5] http://www.36kr.com/p/164343.html

[6] http://www.36kr.com/p/156959.html

[7] http://www.36kr.com/p/156567.html

[8] http://www.36kr.com/p/148052.html 